\title{
Testing of Nebulizers for Delivering Magnesium Sulfate to Pediatric Asthma Patients in the Emergency Department
}

\author{
Allan L Coates MDCM, Kitty Leung, Laurent Vecellio PhD, and Suzanne Schuh MD
}

BACKGROUND: As the use of intravenous magnesium sulfate $\left(\mathrm{MgSO}_{4}\right)$ for the treatment of refractory asthma is becoming more common, the incidence of $\mathrm{MgSO}_{4}$-related systemic hypotension is also rising. One option is to deliver $\mathrm{MgSO}_{4}$ via aerosol, but compared to most inhaled medications, which are active in the microgram dose range, the $\mathrm{MgSO}_{4}$ dose requirement is in the milligram range. This, along with inefficient aerosol delivery systems, may be the reason that some studies have found lack of efficacy with aerosol $\mathrm{MgSO}_{4}$. In preparation for a multicenter study of inhaled $\mathrm{MgSO}_{4}$ in asthmatic children 2-17 years old, we conducted an in vitro study to choose the best $\mathrm{MgSO}_{4}$ nebulizer system that would be effective over the entire age range. METHODS: We tested the Pari LC Star jet nebulizer, Omron MicroAir vibrating-mesh nebulizer, and the Aeroneb Go vibrating-mesh nebulizer with the Idehaler valve-less holding chamber. Aerosol delivery was via face mask. RESULTS: The Pari LC Star had an appropriate particle size distribution but a very slow aerosol output rate. The Omron MicroAir had an even slower output rate and a larger particle size distribution, which would be inappropriate for smaller children. In vitro lung deposition with the Aeroneb Go with Idehaler was $16.0 \pm 0.4 \mathrm{mg} / \mathrm{min}$ in older children and approximately a fifth of that in toddlers. CONCLUSIONS: The Aeroneb Go with Idehaler was chosen for the multicenter clinical study. Key words: aerosol delivery; asthma; pulmonary deposition; magnesium sulfate; nebulizer. [Respir Care 2011;56(3):314-318. (C) 2011 Daedalus Enterprises]

\section{Introduction}

Despite extensive research, standard stabilization therapy for pediatric acute asthma ${ }^{1,2}$ has not substantially im-

\footnotetext{
Allan L Coates MDCM and Kitty Leung are affiliated with the Department of Physiology and Experimental Medicine; and Suzanne Schuh MD is affiliated with the Department of Population Health, Hospital for Sick Children Research Institute, University of Toronto, Toronto, Ontario, Canada. Laurent Vecellio $\mathrm{PhD}$ is affiliated with Aerodrug, and with Institut National de la Santé et de la Recherche Médicale (INSERM), Université François Rableais, Tours, France.
}

The authors have disclosed a relationship with Aerodrug, which is a department of La Diffusion Technique Francaise, Saint Etienne, France.

\footnotetext{
This research was partly supported by Paediatric Consultants Partnership grants from the Hospital for Sick Children Research Institute, Toronto, Ontario, Canada.
}

Correspondence: Allan L Coates MDCM, Hospital for Sick Children Research Institute, 555 University Avenue, Toronto, Ontario, Canada M5G 1X8. E-mail: allan.coates@ sickkids.ca.

DOI: $10.4187 /$ respcare.00826 proved outcomes. ${ }^{3}$ Since many patients do not respond to inhaled $\beta_{2}$ agonists, ${ }^{4}$ and delayed response to corticosteroids is common, the hospitalization rate has remained stable and the related costs are increasing. 5 Two recent meta-analyses found that intravenous magnesium sulfate $\left(\mathrm{MgSO}_{4}\right)$ decreases asthma hospitalization in children by $30 \%,{ }^{6,7}$ and $\mathrm{MgSO}_{4}$ is thus recommended in children with severe asthma resistant to initial bronchodilator therapy. ${ }^{6,8}$ However, intravenous $\mathrm{MgSO}_{4}$ is invasive and requires monitoring for adverse effects. A recent North American survey found that intravenous $\mathrm{MgSO}_{4}$ is uncommonly used, usually to prevent ICU admission rather than hospitalization, and one in 4 physicians have observed the adverse effect systemic hypotension. ${ }^{9}$

In contrast, the inhalation route is noninvasive and offers the advantage of targeted delivery to the lower airways and less potential for toxicity. ${ }^{10}$ Although 2 metaanalyses found a trend toward less hospitalization with nebulized $\mathrm{MgSO}_{4},{ }^{6,11}$ others disagree. ${ }^{12}$ The key limitation is the use of inefficient aerosol delivery methods. None have used the more efficient delivery devices, such as breath-enhanced nebulizer, with which the patient inhales 
through a mouthpiece, or other efficiency-enhancing techniques. Unlike most aerosolized drugs, such as albuterol, which is efficacious in the microgram range, $\mathrm{MgSO}_{4}$, even when given intravenously, is only efficacious in the milligram range and hence requires many-fold higher drug delivery, and there is a physical limitation of the nebulizable volume. Increasing the $\mathrm{MgSO}_{4}$ concentration would increase the delivery rate but is limited by the acceptable aerosol tonicity of approximately $500 \mathrm{mOsm} / \mathrm{L} .{ }^{13}$

With intravenous $\mathrm{MgSO}_{4}$ the greatest lung tissue exposure is in the alveoli, where the vessel wall is the thinnest and the perfusion per gram of tissue is greatest. To reach the airway smooth muscle, intravenous $\mathrm{MgSO}_{4}$ has to diffuse from the thicker-walled pulmonary arteries and arterioles or from the bronchial circulation, which is very small compared to the pulmonary circulation. In contrast, most inhaled $\mathrm{MgSO}_{4}$ would be deposited in the airways, and subsequent direct diffusion through the airway epithelium would result in a much higher magnesium level around the smooth muscle, compared to intravenous administration. Therefore, while the systemically delivered dose of nebulized $\mathrm{MgSO}_{4}$ would probably be lower than with the intravenous route and result in less risk of hypotension, the increased delivery to the airway muscles could result in a similar or greater bronchodilator effect.

The purpose of this pilot study was to investigate the expected $\mathrm{MgSO}_{4}$ pulmonary deposition of efficient modern nebulizers and to choose a nebulizer for a planned multicenter trial of nebulized $\mathrm{MgSO}_{4}$ in pediatric acute asthma in the pediatric emergency department setting. Ideally, a comparison would be made to devices used in other studies, but insufficient details regarding the equipment used made that impossible. To power the clinical study sufficiently to give confidence in the results and to keep the budget within reason, it is essential to use the same aerosol delivery system with all subjects, regardless of age. This necessitates the use of a face mask, since the younger subjects (based on emergency utilization data) are likely to be the largest group. This constraint limited the full potential of breath-enhanced nebulization, which requires a mouthpiece and both inspiratory and expiratory valves.

\section{Methods}

The study was conducted at the Hospital for Sick Children, Toronto, Ontario, Canada.

We tested 3 aerosol systems:

- Aeroneb Go vibrating-mesh nebulizer (Aerogen, Galway, Ireland) with Idehaler holding chamber (La Diffusion Technique, Francaise, St Etienne, France), adapted for use with a face mask. There are no inspiratory or expiratory valves in this system, but the geometry favors aerosol retention during expiration, and then inhalation of both the retained and the generated aerosol during the subsequent inspiration. Given the necessity of using a loose-fitting face mask, preliminary tests suggested that this would be more efficient than other devices. From the investigative perspective, one disadvantage of this valveless system is that adding an expiratory valve to capture aerosol generated but not inhaled would change the fluid dynamics. This precluded a mass balance to determine the accuracy of the measurements.

- MicroAir vibrating-mesh nebulizer (Omron, Kyoto, Japan), used with a face mask. We chose the MicroAir because it has a relatively high aerosol output rate.

- Pari LC Star jet nebulizer (Pari, Munich, Germany), which is a high-efficiency breath-enhanced nebulizer ${ }^{14,15}$ when used in this mode, but less efficient when attached to a mouthpiece. We decided to drive this nebulizer with dry hospital oxygen, because that is what would probably be used clinically. This gave rise to the challenge of choosing a concentration that would allow effective delivery yet have an osmolarity that would not cause bronchospasm, which has been reported when the osmolarity exceeds $500 \mathrm{mOsm} / \mathrm{L} .{ }^{13}$ The Pari LC Star has been extensively studied in our laboratory, and its characteristics are well known, ${ }^{14,15}$ although there was concern about its output rate in the non-breath-enhanced mode that occurs when using a face mask.

For the purpose of this study, we diluted $2 \mathrm{~mL}$ of $\mathrm{MgSO}_{4}$ solution (500 mg $\mathrm{MgSO}_{4}$ per mL, Sandoz, Montreal, Québec, Canada) in $7 \mathrm{~mL}$ of sterile water, then added $1 \mathrm{~mL}$ of albuterol solution (5 mg albuterol per $\mathrm{mL}$, Ventolin Respiratory Solution, GlaxoSmithKline, Montreal, Canada) to give a final solution of $100 \mathrm{mg} / \mathrm{mL}$ of $\mathrm{MgSO}_{4}$ and $500 \mu \mathrm{g} / \mathrm{mL}$ of albuterol, with an osmolarity of $372 \mathrm{mOsm} / \mathrm{L}$. We charged each nebulizer with $6 \mathrm{~mL}$ of that solution. Preliminary data from the Pari LC Star showed both a relatively low aerosol output rate and, because of evaporative loss, an increasing concentration (see below) in the nebulizer reservoir during nebulization. This resulted in higher-than-desired tonicity, ${ }^{16,17}$ so the Pari LC Star was not considered further. Neither of the vibrating-mesh nebulizers have a change in osmolarity during nebulization, because the liquid in the reservoir is not exposed to air until it is nebulized.

An inspiratory filter captured the "inhaled mass" at the device's output (Fig. 1). Since neither the MicroAir nor the Aeroneb Go/Idehaler system has valves, aerosol was drawn through the filter during inspiration and vented into the room during expiration. The inspiratory filter was at the "mouth" of a breath simulator set to a typical adult breathing pattern of 15 breaths $/ \mathrm{min}$, a tidal volume of $0.6 \mathrm{~L}$, and a ratio of inspiratory time to total respiratory cycle time $\left(\mathrm{T}_{\mathrm{I}} / \mathrm{T}_{\text {tot }}\right)$ of $0.4 .{ }^{15,18}$ On the assumption that the 


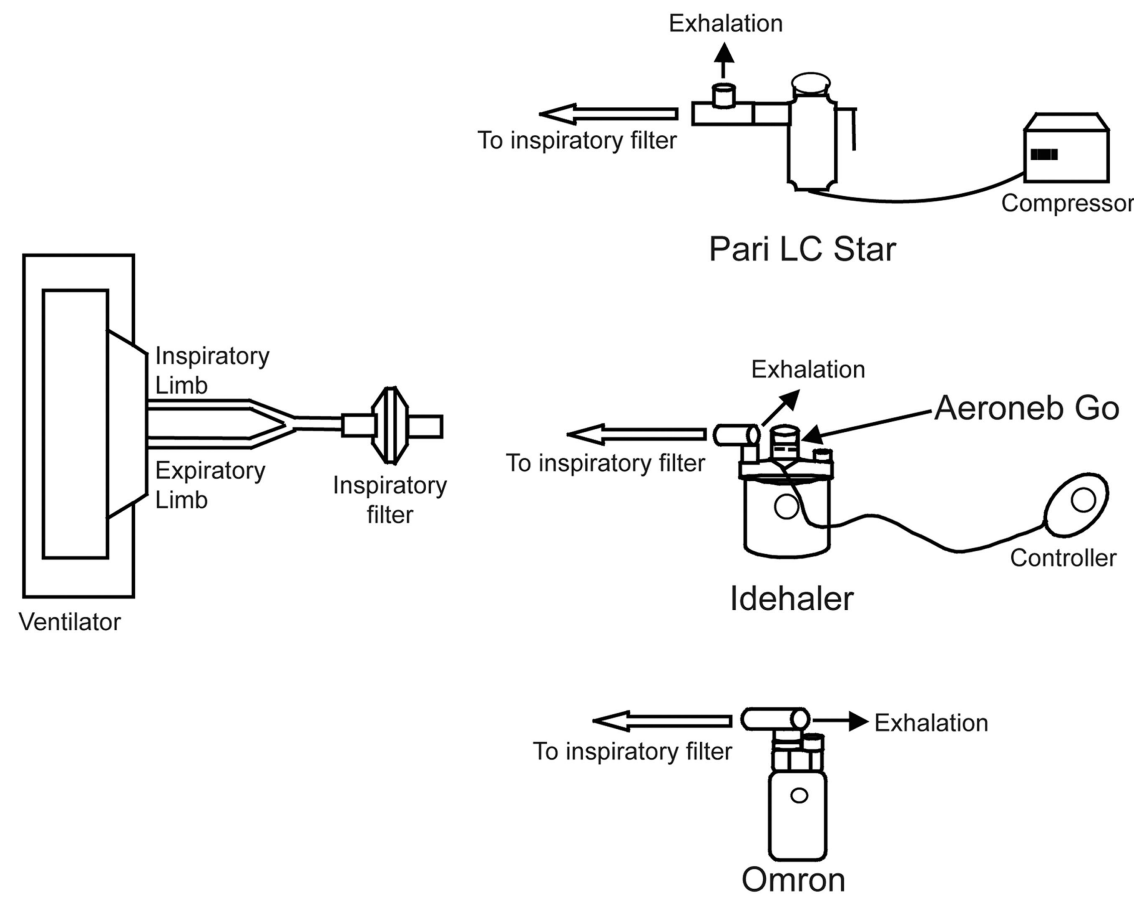

Fig. 1. Setup for bench-testing nebulization of $\mathrm{MgSO}_{4}$-plus-albuterol solution with the Pari LC Star, Omron MicroAir, and Aeroneb Go with Idehaler holding chamber.

solution of $\mathrm{MgSO}_{4}$ would track with the solution of albuterol, we considered the "inhaled mass" the aerosol collected on and eluted from the filter and quantified via spectrophotometry. ${ }^{19}$ Assuming that the deposition of $\mathrm{MgSO}_{4}$ was proportional to the deposition of albuterol on the inspiratory filter, we calculated the rate of $\mathrm{MgSO}_{4}$ deposition. We repeated the test with values representative of a small child ${ }^{20}$ : tidal volume $100 \mathrm{~mL}$, respiratory rate 15 breaths $/ \mathrm{min}$, and $\mathrm{T}_{\mathrm{I}} / \mathrm{T}_{\text {tot }}$ 0.4. Particle size distribution was measured via laser diffraction (Mastersizer X, Malvern Instruments, Worcestershire, United Kingdom) based on the Mie theory. ${ }^{21}$ The volume median diameter is the diameter where $50 \%$ of the aerosol volume is greater than this and $50 \%$ less. Particles $\leq 5 \mu \mathrm{m}$ diameter are likely to deposit in the lungs when inhaled in older children and adults $^{22-25}$ Hence, the fraction of the mass of the aerosol in this size range is known as the respirable fraction. When the amount of aerosol captured on the filter at the "mouth" over a specific time period is multiplied by the respirable fraction, the pulmonary deposition in $\mathrm{mg} / \mathrm{min}$ can be estimated. ${ }^{15}$ There is evidence 20,26 that in younger children the respirable fraction is more appropriately defined as $\leq 4 \mu \mathrm{m}$, and in infants $\leq 3 \mu \mathrm{m}$.

\section{Results}

With the $6 \mathrm{~mL}$ fill, the nebulization time with the Aeroneb Go/Idehaler system was $16.4 \pm 0.7 \mathrm{~min}$, and the mean $\pm \mathrm{SD}$ aerosol output rate was $37.1 \pm 1.5 \mathrm{mg} / \mathrm{min}$. The $\mathrm{MgSO}_{4}$ volume median diameter was $4.4 \pm 0.1 \mu \mathrm{m}$, and the respirable fraction was $59 \pm 0 \%$ with a $\leq 5-\mu \mathrm{m}$ cut-off, $44 \pm 1 \%$ with a $\leq 4-\mu \mathrm{m}$ cut-off, and $28 \pm 2 \%$ with a $\leq 3-\mu \mathrm{m}$ cutoff. With the adult breathing pattern the mean \pm SD inhaled mass was $27.1 \pm 0.6 \mathrm{mg} / \mathrm{min}(n=3)$, which yields a predicted deposition of $16.0 \pm 0.4 \mathrm{mg} / \mathrm{min}$, based on a respirable-fraction cut-off of $\leq 5 \mu \mathrm{m}$ for older children and adults. With an albuterol-to- $\mathrm{MgSO}_{4}$ ratio of $1: 200$, this would mean a pulmonary deposition of $80 \mu \mathrm{g} /$ min. The recommended maximum intravenous infusion of albuterol in our institution is $10 \mu \mathrm{g} / \mathrm{kg} / \mathrm{min}$, so the pulmonary dose would be within that range for any child larger than $10 \mathrm{~kg}$, assuming 100\% delivery and absorption which, in reality, is far from the case. For an adult of $70 \mathrm{~kg}$ the $\mathrm{MgSO}_{4}$ deposition would be $0.23 \mathrm{mg} / \mathrm{kg} / \mathrm{min}$.

In a previous study ${ }^{20}$ of a measles vaccine delivered via nebulizer and face mask, algorithms were developed to look at expected deposition over a wide age range, taking into consideration that both the breathing pattern and the respirable fraction are age-dependent. Based on those algorithms, for the toddler breathing pattern the inhaled mass was $11.3 \pm 0.2 \mathrm{mg} / \mathrm{min}$ with a pulmonary delivery estimate of $3.2 \pm 0.1 \mathrm{mg} / \mathrm{min}$. Therefore a child of $10 \mathrm{~kg}$ would have a deposition of $0.32 \mathrm{mg} / \mathrm{kg} /$ $\min$.

For the adult breathing pattern, the other 2 devices came nowhere near that pulmonary deposition rate. The 
Pari LC Star delivered an estimated $9.0 \pm 0.3 \mathrm{mg} / \mathrm{min}$, and the osmolarity at the end of nebulization exceeded $500 \mathrm{mOsm} / \mathrm{L}$, which is above the suggested safety limit. ${ }^{13}$ The particle size distribution was acceptable, with a respirable fraction of $67 \pm 0 \%$. The MicroAir delivered only $6.6 \pm 0.7 \mathrm{mg} / \mathrm{min}$ to the filter at the "airway" and had a respirable fraction of only $46 \pm 1 \%$, for an estimated deposition of $3.1 \pm 0.3 \mathrm{mg} / \mathrm{min}$ in adults and older children.

\section{Discussion}

The Aeroneb Go/Idehaler system demonstrated superior performance with respect to pulmonary aerosol delivery and optimal particle size while maintaining acceptable osmolarity. Although the Idehaler holding chamber is not yet licensed in North America, the Aeroneb Go is, and few problems are anticipated in getting regulatory approval for the Idehaler. The Pari LC Star has an appropriate particle size distribution but far too slow an aerosol output, and, further complicating the issue, the evaporative loss when driven by a dry hospital gas source rapidly lead to a hyperosmolar aerosol. The MicroAir had neither an appropriate output rate nor particle size distribution. Hence, the Aeroneb Go/Idehaler system best met the requirements of the planned clinical study.

Using a positive study by Ciarallo et al, ${ }^{27}$ the rate of intravenous $\mathrm{MgSO}_{4}$ administration with a dose of $40 \mathrm{mg} / \mathrm{kg}$ for a $25-\mathrm{kg}$ child during a 20 -min infusion would be $50 \mathrm{mg} / \mathrm{min}$. With the Aeroneb Go/Idehaler, the $\mathrm{MgSO}_{4}$ aerosol delivery into the airway would be approximately one fifth that, or $11.2 \mathrm{mg} / \mathrm{min}$, with the "infusion" lasting $16 \mathrm{~min}$. Based on the hypothesis stated above, the high concentration of magnesium in the airway will facilitate diffusion into the interstitial tissue, which includes the airway and the airway capillary bed, from where it will be removed by the circulation. The expected result would be enhanced bronchodilation from the high interstitial concentration of magnesium, with a reduced risk of systemic hypotension because the circulating level would be lower. Since aerosol delivery is only a fraction of the systemic dose given intravenously, 2 more 16-min inhalations could be undertaken with little concern about systemic hypotension.

\section{Limitations}

The first limitation has to do with the prediction of in vivo deposition from an in vitro study where inhaled mass is captured on a filter. When the interface between the device and the subject is a mouthpiece and one way valves, an in vitro study can have inspiratory and expiratory filters so the fate of all the aerosol can be ascertained and a mass balance before and after nebulization can en- sure the accuracy of the results. In this situation, as long as the breath simulator's breathing pattern is appropriate, discrepancies between what enters and stays in the body, compared to what is captured on the inspiratory filter, are due to aerosol that ends up in the patient's anatomical dead space and is exhaled onto the expiratory filter with the next exhalation. With a breath-enhanced nebulizer and a normal subject, the in vitro versus in vivo difference is small. ${ }^{28,29}$ However, the Idehaler system has no valves, and the small but significant resistance of the expiratory filter changed the fluid dynamics in the holding chamber and could not be used. Hence, the concept of mass balance before and after nebulization could not be implemented, and the accuracy of aerosol collection on the inspiratory filter could not be confirmed. Having recognized this, the low standard deviation, compared to the mean for the triplicate studies, would suggest that an error would have to be a systematic one to achieve that degree of repeatability. We recognize that the breathing patterns we used are those of normal children and may not be representative of the breathing pattern during an asthma attack, but there are no data to guide alternative choices.

\section{Conclusions}

Our data suggest that a 16-min nebulization of $6 \mathrm{~mL}$ of the $\mathrm{MgSO}_{4}$-plus-albuterol solution we used, with the Aeroneb Go/Idehaler setup and a face mask would maximize $\mathrm{MgSO}_{4}$ delivery to the airways in severe asthma and prevent bronchospasm due to aerosol hyperosmolarity and hypotension from systemic absorption. Therefore, we recommended this setup for the upcoming multicenter trial of inhaled $\mathrm{MgSO}_{4}$ in children with severe asthma.

\section{REFERENCES}

1. Scarfone RJ, Fuchs SM, Nager AL, Shane SA. Controlled trial of oral prednisone in the emergency department treatment of children with acute asthma. Pediatrics 1993;92(4):513-518.

2. Becker A, Lemière C, Bérubé D, Boulet LP, Ducharme FM, FitzGerald M, Kovesi T; Asthma Guidelines Working Group of the Canadian Network For Asthma Care. Summary of recommendations from the Canadian asthma consensus guidelines, 2003. CMAJ Can Med Assoc J 2005;173(6 Suppl):S3-S11.

3. Kercsmar CM, McDowell KM. Love it or lev it: levalbuterol for severe acute asthma: for now, leave it. J Pediatrics 2009;155(2):162164.

4. Fischl MA, Pitchenik A, Gardner LB. An index predicting relapse and need for hospitalization in patients with acute bronchial asthma. N Engl J Med 1981;305(14):783-789.

5. Weiss KB, Sullivan SD, Lyttle CS. Trends in the cost of illness for asthma in the United States, 1985-1994. J Allergy Clin Immunol 2000;106(3):493-499.

6. Mohammed S, Goodacre S. Intravenous and nebulised magnesium sulphate for acute asthma: systematc review and meta-analysis. Emerg Med J 2007;24(12):832-830. 


\section{Nebulizers for Delivering Magnesium Sulfate}

7. Cheuk DK, Chau TC, Lee SL. A meta-analysis on intravenous magnesium sulphate for treating acute asthma. Arch Dis Child 2005; 90(1):74-77.

8. Aggarwal P, Sharad S, Handa R, Dwiwedi SN, Irshad M. Comparison of nebulised magnesium sulfate and salbutamol combined with salbutamol alone in the treatment of acute bronchial asthma: a randomised study. Emerg Med J 2006;23(5):358-362.

9. Schuh S, Macias C, Freedman S, Plint A, Zorc J, Baja JL, et al. North American practice patterns of IV magnesium therapy in severe acute asthma in children. Acad Emerg Med 2010;17(11):11891196.

10. Okayama H, Aikawa T, Okayama M, Sasaki H, Mue S, Takishima $\mathrm{T}$. Bronchodilating effect of intravenous magnesium sulfate in bronchial asthma. JAMA 1987;257(8):1076-1078.

11. Blitz M, Blitz S, Beasely R, Diner BM, Hughes R, Knopp JA, Rowe $\mathrm{BH}$. Inhaled magnesium sulfate in the treatment of acute asthma. Cochrane Database Syst Rev 2005;(4):CD003898.

12. Villeneuve EJ, Zed PJ. Nebulized magnesium sulfate in the management of acute exacerbations of asthma. Ann Pharmacother 2006; 40(6):1118-1124.

13. Dodd ME, Abbott J, Maddison J, Moorcroft AJ, Webb AK. Effect of tonicity of nebulized colistin on chest tightness and pulmonary function in adults with cystic fibrosis. Thorax 1997;52(7):656-658.

14. Ho SL, Kwong WTJ, Coates AL. Evaluation of four breath-enhanced nebulizers for home use. J Aerosol Med 2001(4):14:467-475.

15. Katz SL, Adatia I, Louca E, Leung K, Humpl T, Reyes JT, Coates AL. Nebulized therapy for childhood pulmonary hypertension: an in vitro model. Pediatr Pulmonol 2006;41(7):666-673.

16. O'Callaghan C, Clarke AR, Milner AD. Inaccurate calculation of drug output from nebulisers. Eur J Pediatr 1989;148(5):473-474.

17. Coates AL, MacNeish CF, Lands LC, Smountas A, Meisner D, Kelemen S, Vadas EB. Factors influencing the rate of drug output during the course of wet nebulization. J Aerosol Med 1998;11(2): 101-111.

18. Coates AL, MacNeish CF, Allen PD, Ho SL, Lands LC. Do sinusoidal models of respiration accurately reflect the respiratory events of cystic fibrosis patients breathing on nebulizers? J Aerosol Med 1999;12(4):265-273.
19. Leung K, Louca E, Coates AL. Comparison of breath enhanced to breath actuated nebulizers for rate, consistency, and efficiency. Chest 2004;126(5):1619-1627.

20. Coates AL, Tipples G, Leung K, Gray M, Louca E; WHO Product Development Group for Measles Aerosol Vaccine. How many infective particles are necessary for successful mass measles immunization by aerosol? Vaccine 2006;24(10):1578-1585.

21. Mitchell JP, Nagel MW, Nichols S, Nerbrink O. Laser diffractometry as a technique for rapid assessment of aerosol particle size from inhalers. J Aerosol Med 2006;19(4):409-433.

22. Coates AL, MacNeish CF, Meisner D, Kelemen S, Thibert R, MacDonald J, Vadas EB. The choice of jet nebulizer, nebulizing flow and the addition of Ventolin respiratory solution affects tobramycin aerosols used in cystic fibrosis. Chest 1997;111(5):1206-1212.

23. MacNeish CF, Meisner D, Thibert R, Kelemen S, Vadas EB, Coates AL. A comparison of pulmonary availability between Ventolin (albuterol) nebules and Ventolin (albuterol) respirator solution. Chest 1997;111(1):204-208.

24. Newman SP, Pellow PG, Clay MM, Clarke SW. Evaluation of jet nebulisers for use with gentamycin solution. Thorax 1985;40(9):671676.

25. Clay MM, Pavia D, Newman SP, Clarke SW. Factors influencing the size distribution of aerosols from jet nebulisers. Thorax 1983;38(10): 755-759.

26. Janssens HM, de Jongste JC, Fokkens WJ, Robben SG, Wouters K, Tiddens HA. The Sophia anatomical infant nose-throat (SAINT) model: a valuable tool to study aerosol deposition in infants. J Aerosol Med 2001;14(4):433-441.

27. Ciarallo L, Brousseau D, Reinert S. Higher dose intravenous magnesium sulfate therapy for children with moderate to severe acute asthma. Arch Pediatr Adolesc Med 2000;154(10):979-983.

28. Coates AL, MacNeish CF, Dinh L, Rollin T, Gagnon S, Ho SL, Lands LC. Accounting for radioactivity before and after nebulization of tobramycin to insure accuracy of quantification of lung deposition. J Aerosol Med 2000;13(3):169-178.

29. Coates AL, Green M, Leung K, Louca E, Tservistas M, Chan J, et al. The challenges of quantitative measurement of lung deposition using ${ }^{99 \mathrm{~m}} \mathrm{Tc}$-DTPA from delivery systems with very different delivery times. J Aerosol Med 2007;20(3):320-330. 